\title{
إنتاج بروتين محور من أسمالك الجري Silurus triostequs ودر استة صفاته النوعية في الانظمة الغذائية
} بتول عبد الرحيم أحمد و فرح طارق حمد الأهان

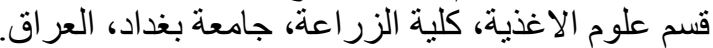

E-mail: abdulrahemb@yahoo.com

$$
\text { مقبول للنشر في: 2015/4/29 }
$$

الخلاصة فئة

هدف الدراسة هو نتاج مركز بروتيني محور من الألياف العضلية لأسماك الجري Silurus triostegus ودراسة تركيبه

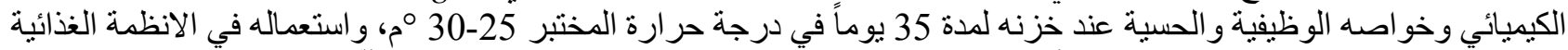

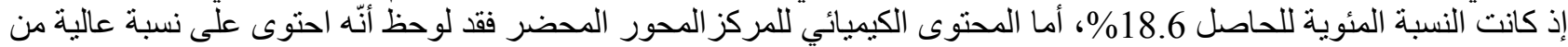

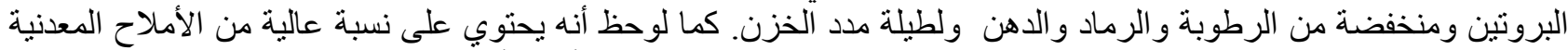

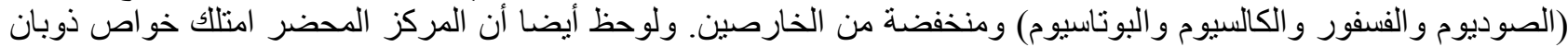

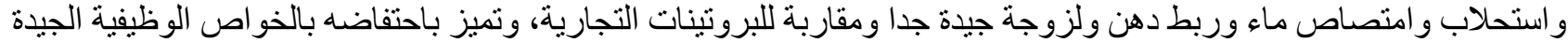

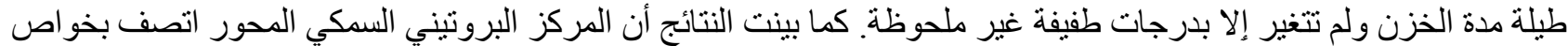

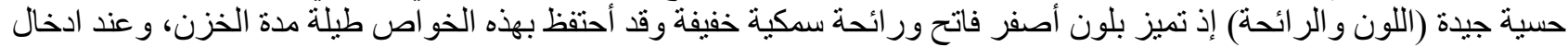

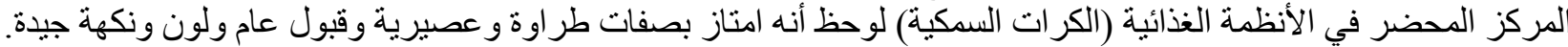

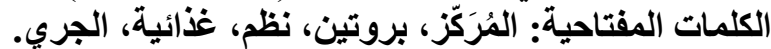

الجري وسمك الخشني أن نسبة الحاصل من المركز

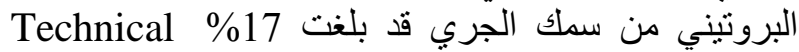
Food grade \%16 grade بلغت نسبة الحاصل 18\% \% و 917\% Food grade

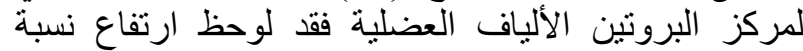

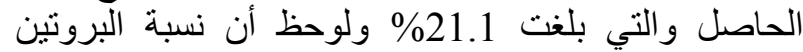

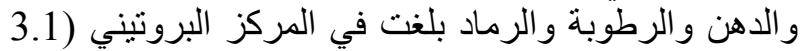

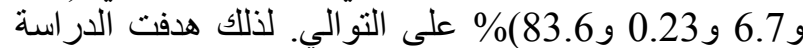

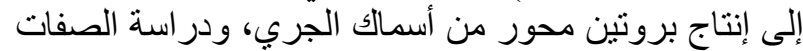
النوعية للمركز البروتيني الناتج و واستعماله في الأنظمة النيات

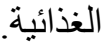

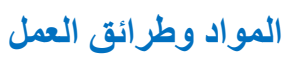

شملت الدراسه أسماك الجري الموجودة في أسواق بغداد الزئ المحلية، وقد أزيلَ منها الجلد والرأس و الأحشاء الداخلية

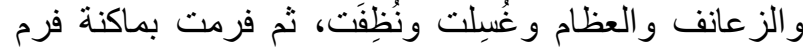

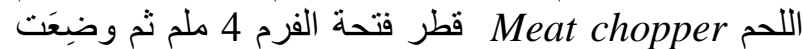

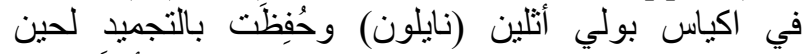

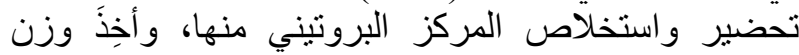

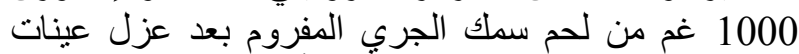

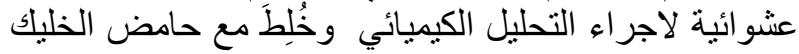

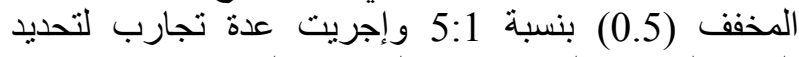

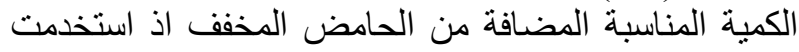

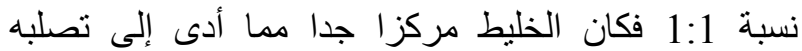

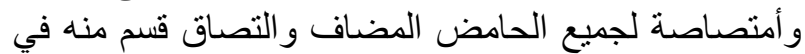
الدورق الذي يحويه عند رفع درجة حرارتها لارنه في الخطوة

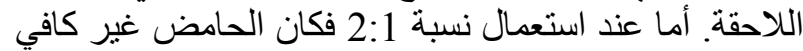

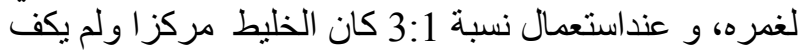

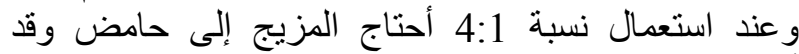

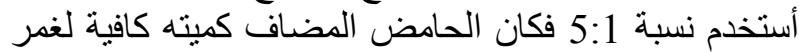
اللحم الدفروم وعدم التصاقه بجدران الدورق في في أثناء

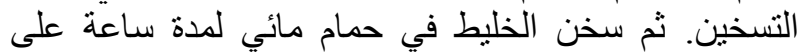

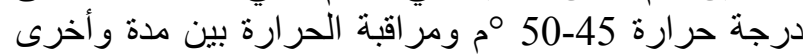

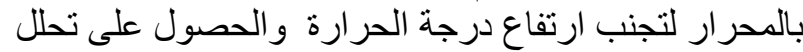

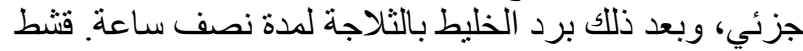

المقدمة

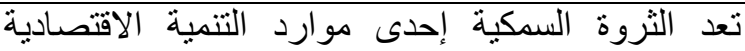

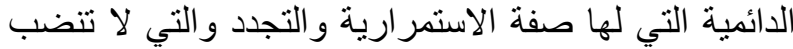

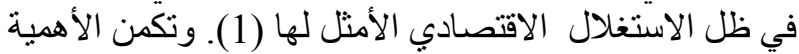

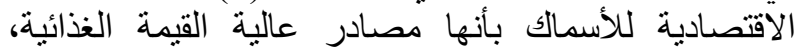

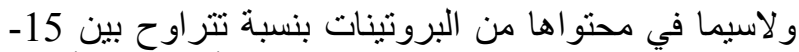
24\% و التي تتميز باحتو ائها على جميع الأحماض الأني الأمينية

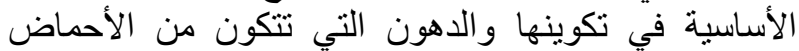

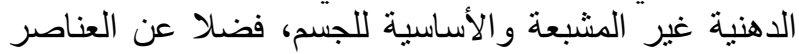

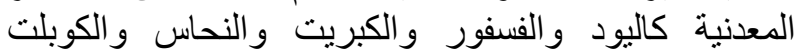

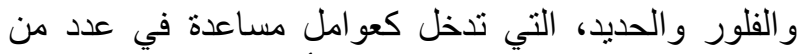

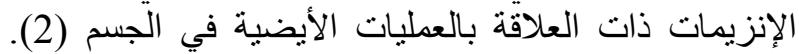

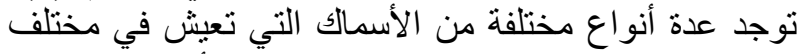

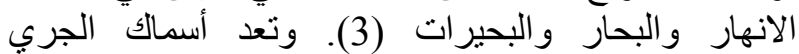
Silurus triostegus

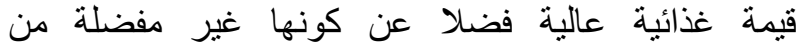
المستهلاك، وتوجد في جميع مناطق العراق التية وتكثر في المياه

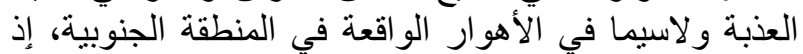

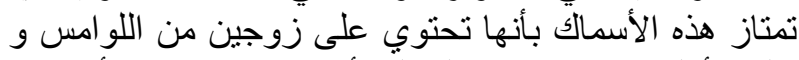

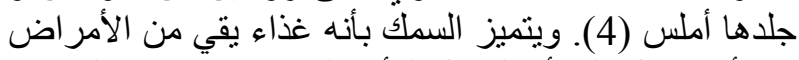

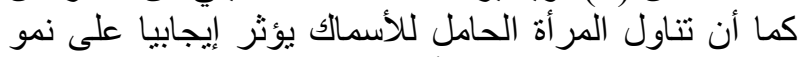

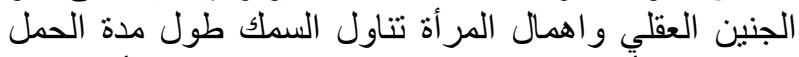

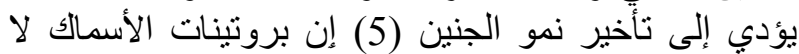

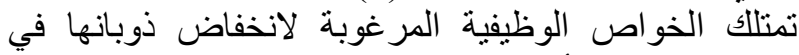

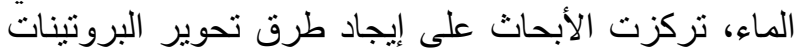

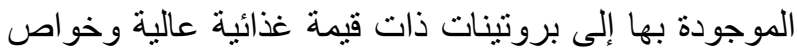
و طبيعة ممتازة وذللك باستعمال الطر ائق الكيميائية و الطر ائق القئ

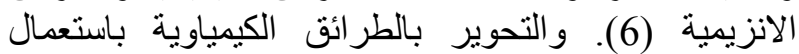

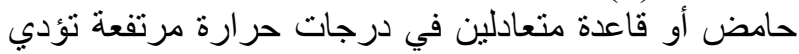

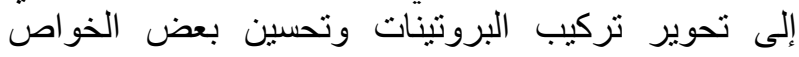

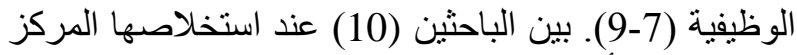

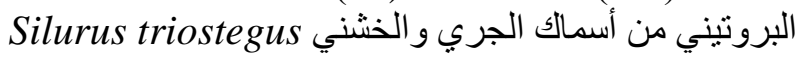

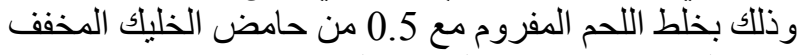
واستخلصت نوعين من المركز البروتيني هما Technical Food grade grade من نوعين من الأسماك هما سمك الهك 


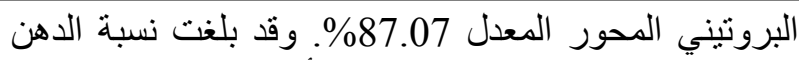

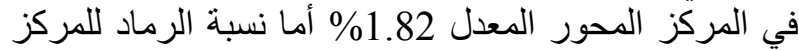

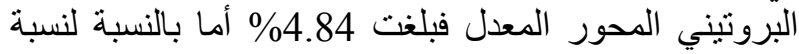
الحاصل للمركز البروتيني السمكي إذ بلغت 18.6 18.

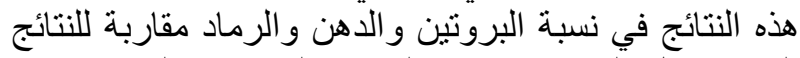

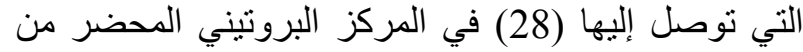

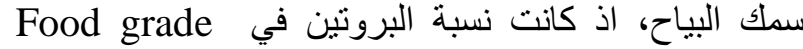

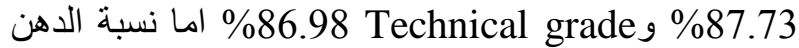

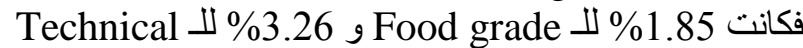

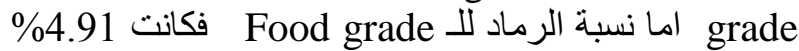
بينما لا

جدول، 1: المحتوى الكيميائي للألياف العضلية لسمك الجري.

\begin{tabular}{|c|c|}
\hline النسبة المئوية \% & المكونـات \\
\hline 76.9064 & الئوبة \\
\hline 18.3296 & البروتين \\
\hline 1.2097 & الرماد \\
\hline 2.9825 & الدهن \\
\hline
\end{tabular}

\begin{tabular}{|c|c|c|c|c|c|c|}
\hline المجموع & $\begin{array}{l}\text { ألد هن } \\
(\%)\end{array}$ & $\begin{array}{l}\text { اليرماد } \\
\text { (\%) }\end{array}$ & البروتين & الرطوبة (\%) & $\begin{array}{c}\text { (اص) } \\
(\%)\end{array}$ & البمكي \\
\hline 99.08 & 1.82 & 4.84 & 87.07 & 5.35 & 18.6 & المعرى المعل \\
\hline
\end{tabular}

تشير النتائج في (جدول، 3) إلى أن المركز البروتيني

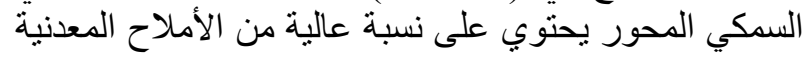

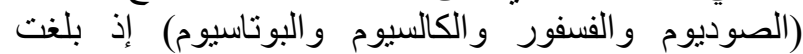

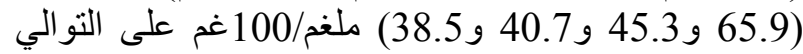

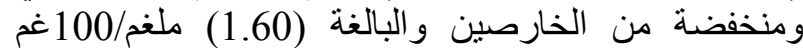

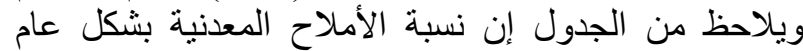

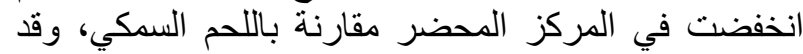
يعود السبب في هذا الانخفاض إلى عملية الغسل المنكرر التئي التئي تعرض لها اللحم بعد المعادلة بالحامض عند تحضير المركز.

\begin{tabular}{|c|c|c|c|c|c|}
\hline خارصين & فَسفور & بوتاسيوم & صوديوم & |كالسبيوم| & العينة \\
\hline 2.5 & 178.3 & 163.7 & 144.5 & 169.8 & لهم سمك الجزي \\
\hline 1.60 & 45.3 & 38.5 & 65.9 & 40.7 & البروتين المعدور \\
\hline
\end{tabular}

يبين (جدول، 4) تأثثر المدد الخزنية على المحتوى الذئي

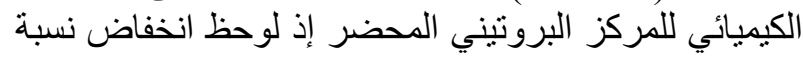

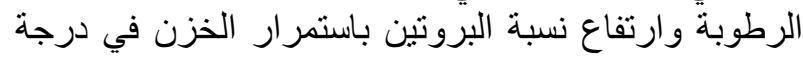

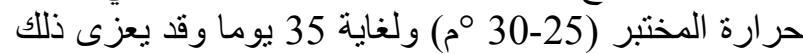

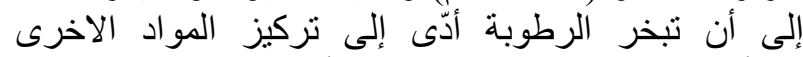

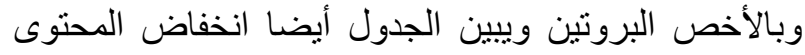

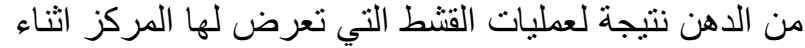

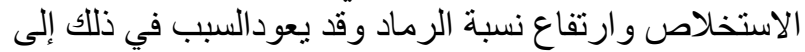

الأهن الموجود على السطح المتكون على هيأة بقع صغيرة

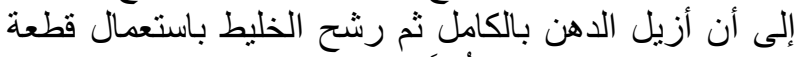

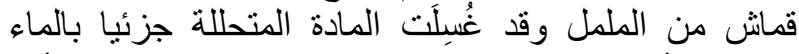

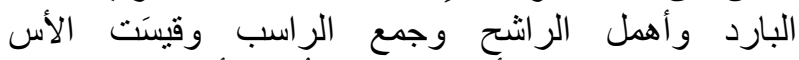

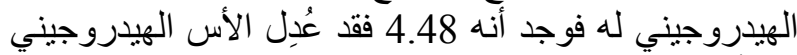

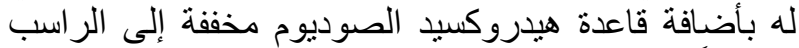

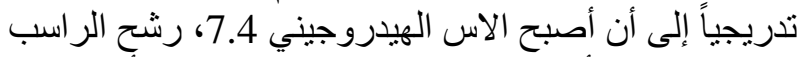

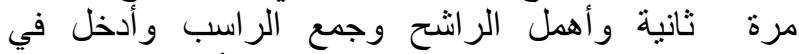

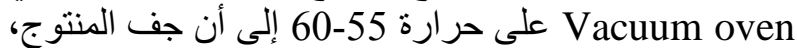

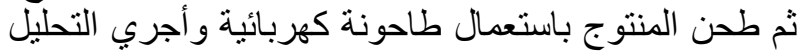

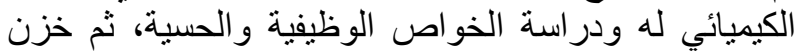

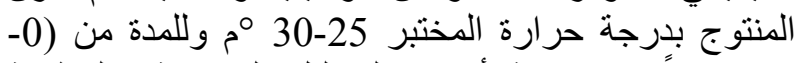
35) يوماً مع متابعة أجراء التحاليل الكيميائية والوظيفية و الحسية طيلة مدة الخزن. وقد استعملت طريقة Semi-microkjeldahl لتقدة التقدير النتروجين كما وضحها (12) وضرب الناتجاتج في الثابت العام

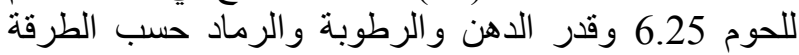
Flame المذكورة في(13) واستعمل جهاز اللهب الضئ الرمائي photometer في تقدير الأملاح المعدنية (الصوديوم

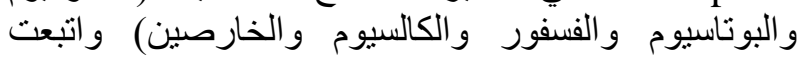
الطريقة المذكورة في (14) لتحضير العينات للقياس. والفئرة وقدّر

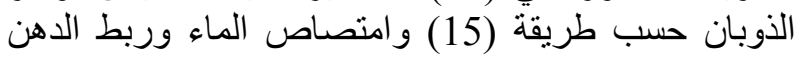
حسب طريقة (16) و الاستحلاب تبعا لطريقة (17) ولنيان (17) والرغونة تبعا لطريقة (18) و اللزوجة حسب طريقة (19) (19) و التهليم حسب طريقة (20). وقد حُسِبَت النسبة المئوية لحاصل المركز البروتيني

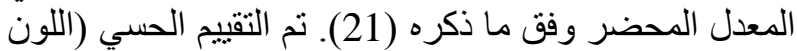

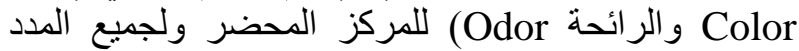

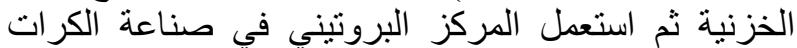
السمكية وفق ما ذكره (22) وأجري التقيية التيبم الحسي للكرات

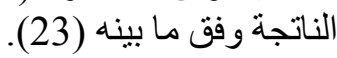

\section{النتائج و المناقشية}

يبين (جدول، 1) المحتوى الكيميائي للألياف العضلية

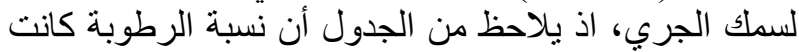

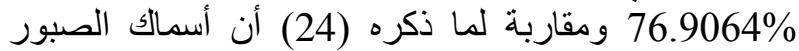

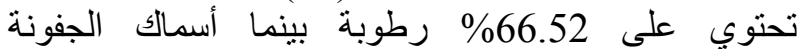

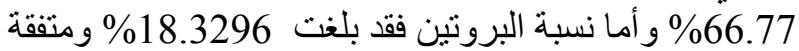

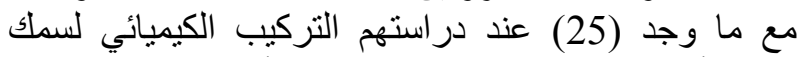
البياح أن نسبة البروتين فيه 18.7\% أما نسبة الرماد فقد

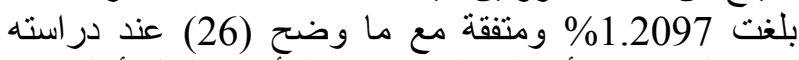

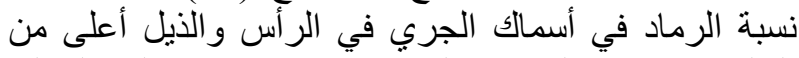

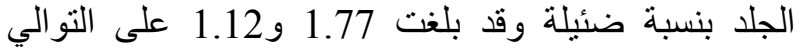

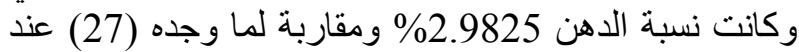

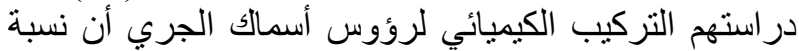

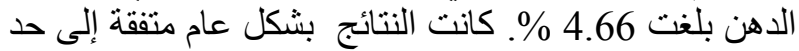

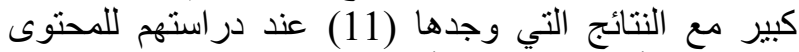
الكيميائي للألياف العضلية لأسماك الجري الجيات يوضح (جدول، 2) نسبة الحاصل ولائل المحتوى الكيميائي

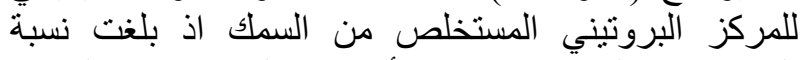
الرطوبة في المركز 5.35\%، أما نسبة البروتين في المركز 
أعبة كبيرة من الأحماض الأمينية المحبة للماء. فقد لوحظ أنّ الهي

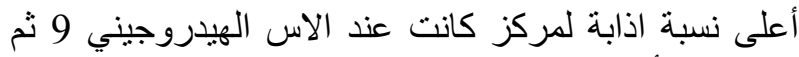

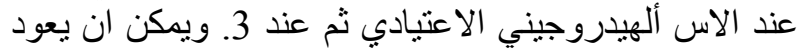

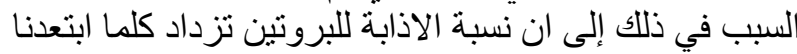

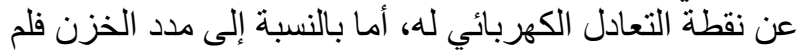

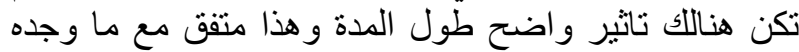

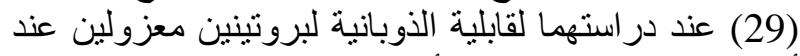

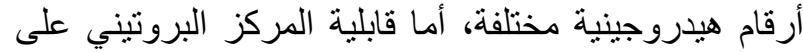

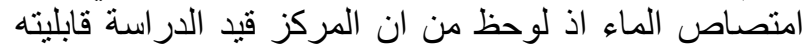

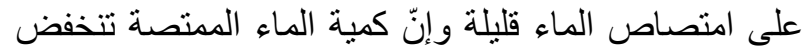

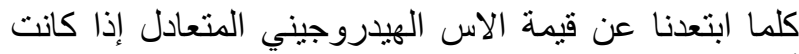

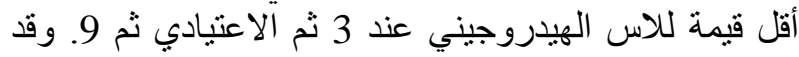

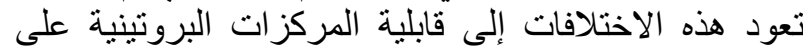

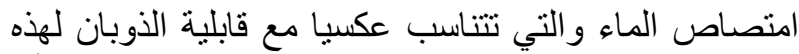

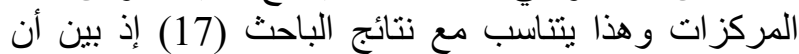
قابلية البروتين على امتصاص الماء تقل كلما زاد قابلية

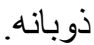

عملية الغسل بالماء التي خضع لها المركز البروتيني المحور

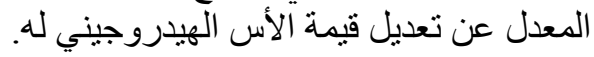

جدول، 4: التغيرات في المحتوى الكيميائي للمركز البروتيني المعلد

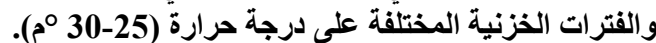

\begin{tabular}{|c|c|c|c|c|c|c|}
\hline 35 & 28 & 21 & 14 & 7 & $\mathbf{0}$ & فترة الخزن (يوم) \\
\hline 3.25 & 3.36 & 3.56 & 3.92 & 4.52 & 5.35 & الرطوبة \% \\
\hline 5.32 & 5.29 & 5.22 & 5.13 & 5.00 & 4.84 & الرماد \% \\
\hline 88.45 & 88.32 & 88.17 & 87.95 & 87.60 & 87.07 & البروتين \% \\
\hline 1.94 & 1.92 & 1.92 & 1.89 & 1.86 & 1.82 & 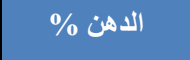 \\
\hline
\end{tabular}

ويبين (جدول، 5) النسبة المئوية لذوبان لمركز البروتيني

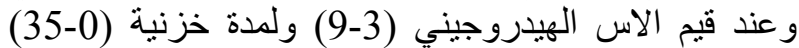

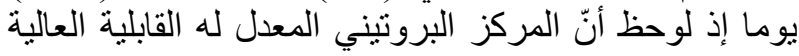

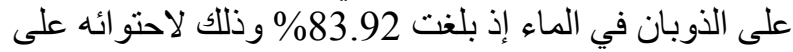

الجدول، 5: النسبة المئوية للأوبان وامتصاص الماء وربط الدهن ولمدة خزن 35 يوما للبروتين السمكي.

\begin{tabular}{|c|c|c|c|c|c|c|c|}
\hline \multicolumn{6}{|c|}{ مدة النزن (يوم) } & \multirow{2}{*}{$\begin{array}{c}\text { الكيدروجيني } \\
\text { (PH) }\end{array}$} & \multirow[b]{2}{*}{ الخاصية } \\
\hline 35 & 28 & 21 & 14 & 7 & $\mathbf{0}$ & & \\
\hline 78.26 & 78.25 & 78.24 & 78.22 & 78.20 & 78.16 & 3 & \multirow{4}{*}{ الأويان } \\
\hline 84.00 & 84.00 & 83.99 & 83.97 & 83.96 & 83.92 & الاعتيادي & \\
\hline 87.19 & 87.17 & 87.17 & 87.15 & 87.15 & 87.12 & 9 & \\
\hline 1.71 & 1.73 & 1.73 & 1.73 & 1.75 & 1.75 & 3 & \\
\hline 1.96 & 1.96 & 1.96 & 1.99 & 1.99 & 2.00 & الاعتيادي & \multirow[t]{2}{*}{ امتصاص الماء } \\
\hline 1.55 & 1.56 & 1.56 & 1.56 & 1.58 & 1.60 & 9 & \\
\hline 1.88 & 1.87 & 1.87 & 1.87 & 1.85 & 1.85 & 1.85 & ربط الدهن \\
\hline
\end{tabular}

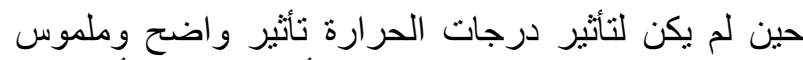

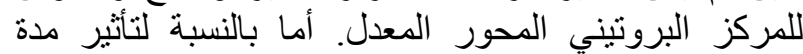

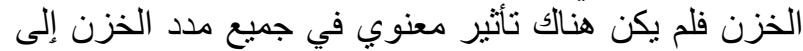

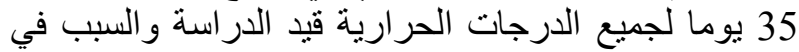

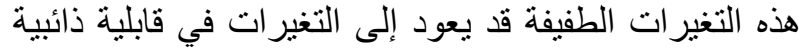

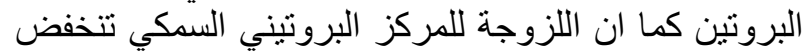

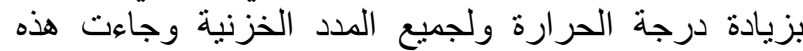

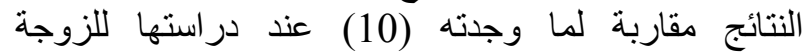

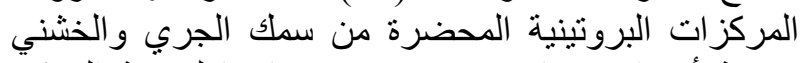

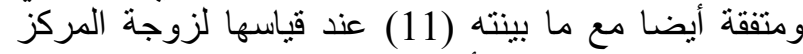

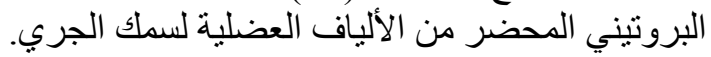

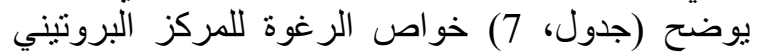

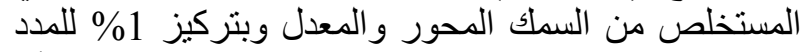

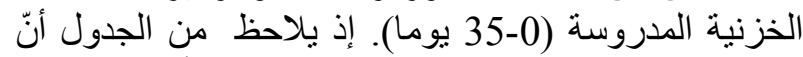

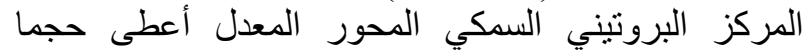

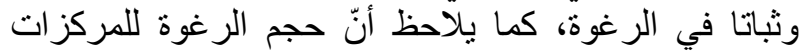

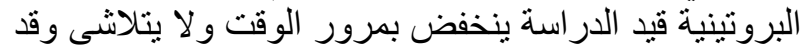

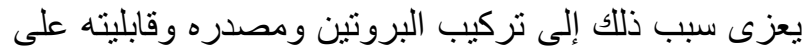

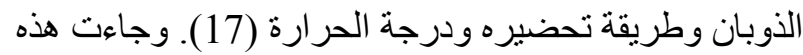

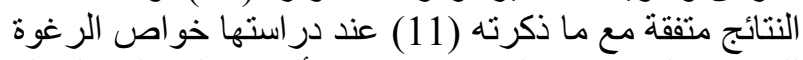

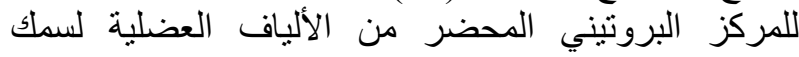

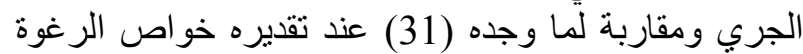

أما تاثير مدة الخزن في كمية الماء الممتصة في المركز

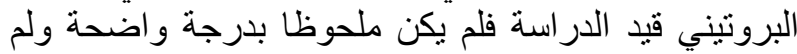

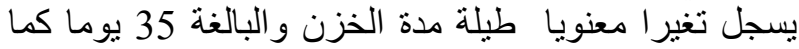

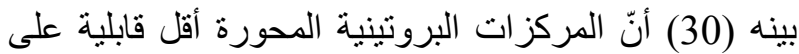

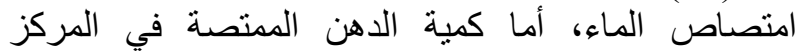

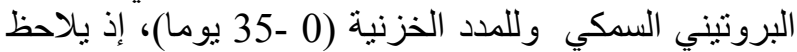

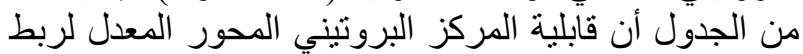

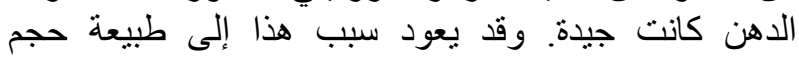

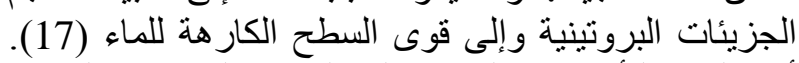

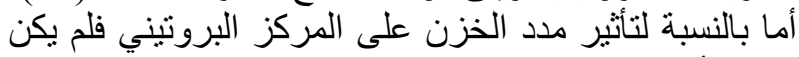

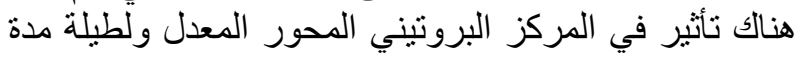

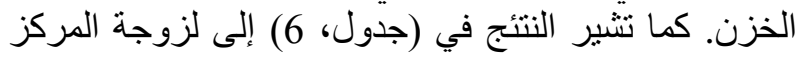

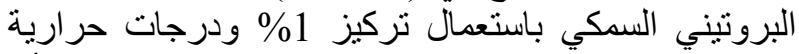

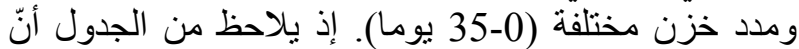

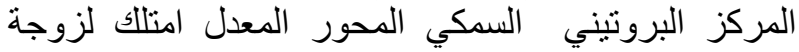

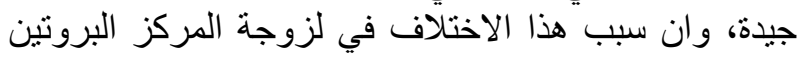

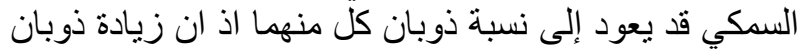

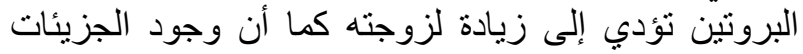

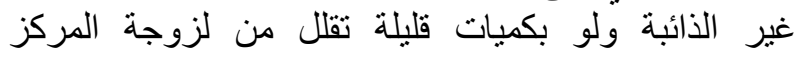

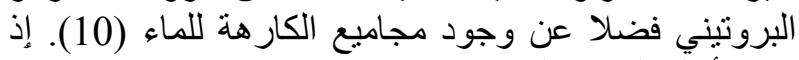

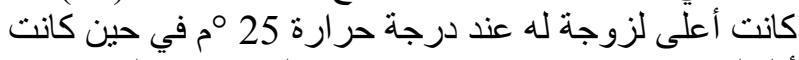

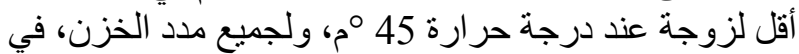


لتأثثيرمدةالخزن تأثير واضح على خو اص الرغوة طورة طيلة المدة

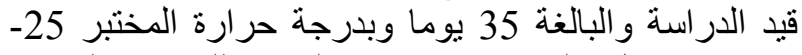

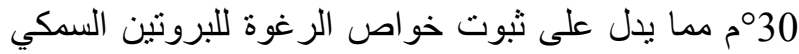

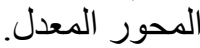

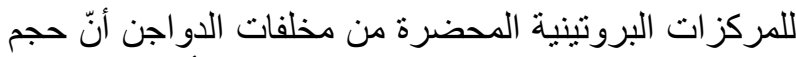

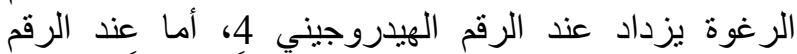

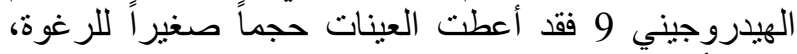
وبين أن حجم الرغوة يقل مع زيادة الوقت، ولم يكن للرغن

الجدول، 6: لزوجة المركز البروتيني السمكي ( سنتي بويز ) باستعمال 1\% ودرجات حرارية ومدد خزن مختلفة.

\begin{tabular}{|c|c|c|c|c|c|c|}
\hline \multicolumn{6}{|c|}{ درجة الحرارة (م) } & \multirow[b]{2}{*}{ البروتين } \\
\hline 45 & 40 & 35 & 30 & 25 & مدة الخزن (يوم) & \\
\hline 0.7024 & 0.7366 & 0.7780 & 0.8003 & 0.8563 & 0 & \multirow{6}{*}{ المحور المعدل } \\
\hline 0.7031 & 0.7372 & 0.7787 & 0.8013 & 0.8572 & 7 & \\
\hline 0.7037 & 0.7379 & 0.7792 & 0.8021 & 0.8585 & 14 & \\
\hline 0.7039 & 0.7382 & 0.7795 & 0.8029 & 0.8590 & 21 & \\
\hline 0.7045 & 0.7385 & 0.7796 & 0.8033 & 0.8597 & 28 & \\
\hline 0.7047 & 0.7386 & 0.7798 & 0.8037 & 0.8599 & 35 & \\
\hline
\end{tabular}

جدول، 7: خواص الرغوة للمركز البروتيني السمكي المحور بتركيز 1\% للمدة الخزنية المدروسة.

\begin{tabular}{|c|c|c|c|c|c|}
\hline \multicolumn{4}{|c|}{ الوقتث (دقيقةة) } & & \multirow[b]{2}{*}{ البروتين } \\
\hline 60 & 30 & 10 & 0 & مدد الخزن (يوم) & \\
\hline 15 & 25 & 40 & 125 & $\mathbf{0}$ & \multirow{6}{*}{ لمحور المعدل } \\
\hline 15 & 25 & 35 & 125 & 7 & \\
\hline 13 & 25 & 35 & 125 & 14 & \\
\hline 13 & 25 & 35 & 122 & 21 & \\
\hline 15 & 25 & 35 & 125 & 28 & \\
\hline 15 & 25 & 35 & 125 & 35 & \\
\hline
\end{tabular}

وجاءت نتائج الاستحلاب هذه مقاربة أيضا لما توصلت اليه

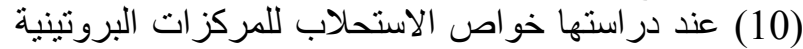

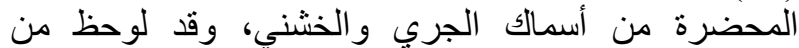
الجداول أيضا أنّ ثباتية المستحلبات للمركزية ات البرونية البروتينية

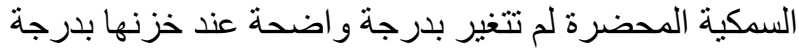

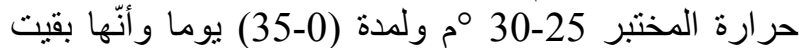
ثابته طيلة مدة الخزن، وجاءت هذه النتائج متفقة مع ماذكرته

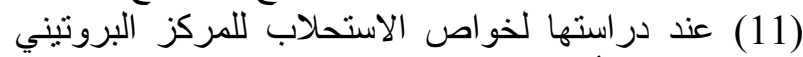

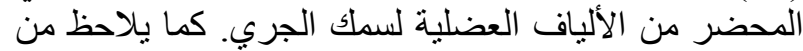

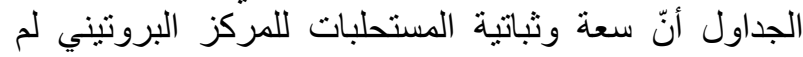

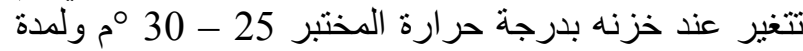

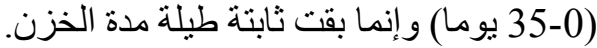

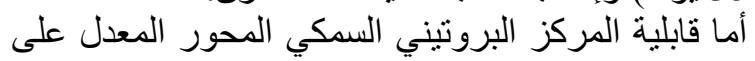

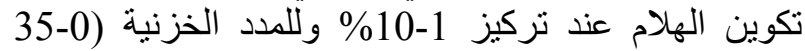

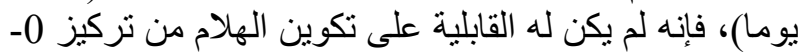

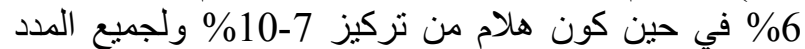

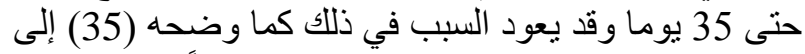

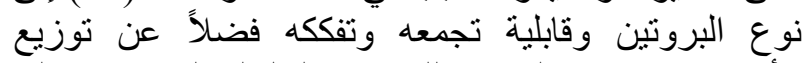
الأحماض الامينية الكار هة للماء في السلسلة البروتينية و إلى فئي

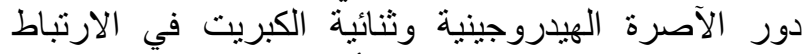

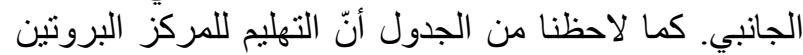

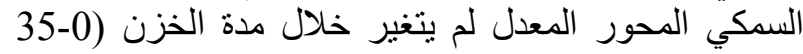

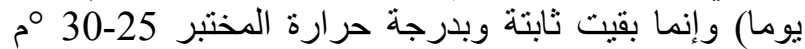
وهذا يتفق مع ما وجدته عبد الرحيم (36) عند درانة دراستها خاصية التهليم للبروتين المستخرج من ون العظام كما كانت منفقة
تشير النتائج في (جدول، 8) لثباتية المستحلب للمركز البروتيني المحور المعدل (1 غم من العينة مع 50 مل من من من

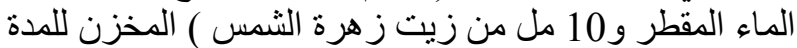
من (0 -35 يوما). إذ نبين النتائج عند منابعة ثباتية المستحلب مهن

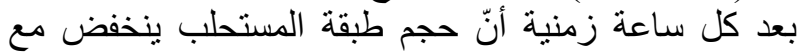
مرور الوقت ويقابلها زيادة في حجم طبقة الماء، وقد لوحن لوحظ أنّ زمن انكسار الطبقة الكريمية بلغ عدة ثوانِ في في المركز

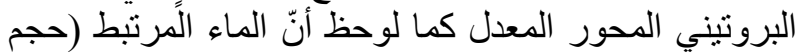
المستحلب النهائي - حجم الزيت المضاف) كان قليلا وقد الند يعود السبب في ذللك إلى انخفاض قابلية المركز البروتيني على حمل الماء (32). وتبين الجداول أنّ المركز البروتيني السمكي المحور المعدل كان أكثر ثباتية ويعلل ذللك بأن ثباتية

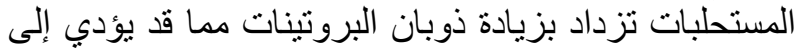

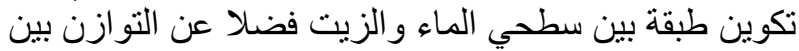

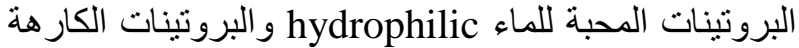
للماء (33) (34) و وجاءت هذه النتائج متفقة مع

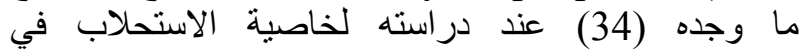
المركزات البروتينية المحضرة من سمك الحف وبف وباستعمال عدة تحوير ات مستعملا الخل وتر اكيز ملحية مختلفة، كما بين التهن أنّ هناك عدة عوامل نؤثر على الاستحلاب وفي مقدمتها

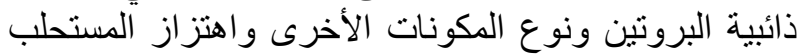

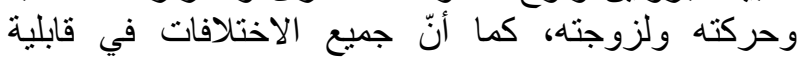

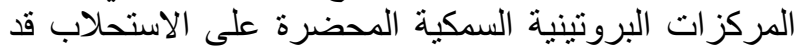

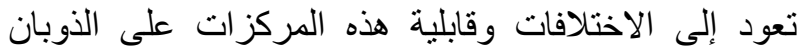
والتي تعد من العوامل المهمة والمؤثرة على الألى الاتحلاب 
و عديم الرائحة وقد أحتفظ بهذه الصفات طبلة المدد الخزنية،

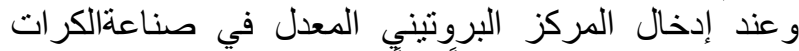
السمكية لوحظ انه كان جيداً جداً كما في (جدول، 9) فئول.
مع النتائج التي توصل إليها (10 و34) عند تقدير هما لخاصية

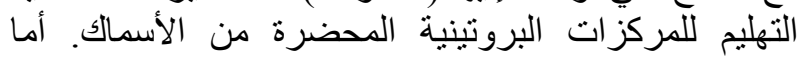
الصفات الحسيه للمركز المعدل فإنه كان ذو لونة الصن الصفر فاتح الماك

الجدول، 8: ثباتية المستحلب (اغم عينة + 50 مل ماء مقطر + 10 مل زيت زهرة الشمس ) للمدد(0-35 يوما).

\begin{tabular}{|c|c|c|c|c|c|c|c|c|}
\hline ساعة 24 & $\begin{array}{c}4 \\
\text { ساعة }\end{array}$ & ساعة 3 & ساعة 2 & ساعة 1 & * & 0 & الوقت & مدد النزن \\
\hline 17 & 17 & 21 & 21 & 22 & 25 & 59 & طبقة المستحلب & \multirow[t]{2}{*}{0} \\
\hline 42 & 42 & 38 & 38 & 37 & 34 & $\mathbf{0}$ & طبقة الماء & \\
\hline 21 & 21 & 21 & 21 & 22 & 27 & 59 & طبقة المستحلب & \multirow[t]{2}{*}{7} \\
\hline 38 & 38 & 38 & 38 & 37 & 32 & $\mathbf{0}$ & طبقة الماء & \\
\hline 22 & 22 & 22 & 22 & 22 & 27 & 59 & طبقة المستحلب & \multirow[t]{2}{*}{14} \\
\hline 37 & 37 & 37 & 37 & 37 & 32 & 0 & طبقة الماء & \\
\hline 22 & 22 & 22 & 22 & 22 & 27 & 59 & طبقة المستحلب & \multirow[t]{2}{*}{21} \\
\hline 37 & 37 & 37 & 37 & 37 & 32 & $\mathbf{0}$ & طبقة الماء & \\
\hline 22 & 22 & 22 & 22 & 22 & 28 & 59 & طبقة المستحلب & \multirow[t]{2}{*}{28} \\
\hline 37 & 37 & 37 & 37 & 37 & 31 & $\mathbf{0}$ & طبقة الماء & \\
\hline 17 & 17 & 17 & 22 & 22 & 26 & 59 & طبقة المستحلب & \multirow[t]{2}{*}{35} \\
\hline 42 & 42 & 42 & 37 & 37 & 33 & $\mathbf{0}$ & طبقة الماء & \\
\hline
\end{tabular}

جدول ،9: التقييم الحسي لمنتوج الكرات السمكية.

\begin{tabular}{|c|c|c|c|c|c|}
\hline $\begin{array}{c}\text { Overall } \\
\text { Occeptability } \\
\text { acceng }\end{array}$ & $\begin{array}{c}\text { الطراوة } \\
\text { Tender-ness }\end{array}$ & 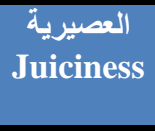 & $\begin{array}{l}\text { agsil } \\
\text { flavor }\end{array}$ & $\begin{array}{l}\text { Color } \\
\text { Color }\end{array}$ & المنتج المصضر \\
\hline 6.00 & 5.75 & 5.50 & 5.75 & 6.25 & العينة القياسبة \\
\hline 6.00 & 6.50 & 6.00 & 5.50 & 6.25 & اضافة 5\% بروتين المحور المعدل \\
\hline 6.50 & 6.25 & 6.25 & $\mathbf{5 . 5 0}$ & 6.00 & اضافة 10\% بروتين الفحور الهعدل \\
\hline
\end{tabular}

Whitaker, Washington DC: American Chemical Society. Pp: 95-155.

7. Lawal, O. S.; Adebowale. K. G. and Adebowale Y. A. (2007). Functional properties and chemically modified protein concentrate from bambarra gronnd food Res. intential, 40:1003-1011.

8. Hamada, J. S. (1994). Deamidation of food proteins to improve functionality. eritical Reviews in food science and nutrition. 34: 283-292.

9. Dilollo, A.; Ali, B. C. and Bar T. N. (1993). Thermal and surface active properties of citric acid- extracted and alkalieetracted oroteins from phaseo lus beaus. J. Agric. food chem., 41: 24-27.

10. اليونس، زينة كاظم عيسى (2002). تحضير البومين ماتئ السمك ودراسة صفاته النوعية. رسالة ماجستير، كلية الزية

$$
\text { الزر اعة - جامعة البصرة. }
$$

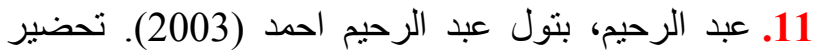

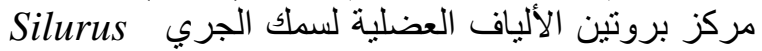
triosfegus

و الحسية مجلة البصرة لأبحاث الطب ألبيطري. 1(1):2:

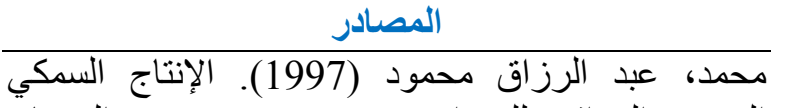
البحري العراقي للسنوات 1965- 1992. 1992، في الإني المصايدي

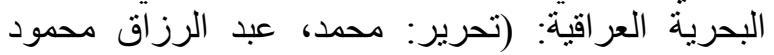

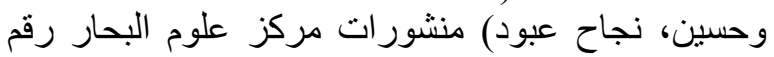
.43-31:22 2. المنظمة العربية للتنمية الزر اعية. (1996). الفنية والاقتصادية لإنتاج الاعلاف السمكية من مصنية التصادر

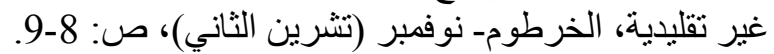

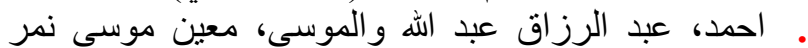

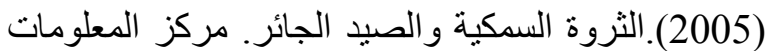
الزر اعية. وزارة الزر اعة والثرة الثروة السمكيية دولة الامار اتركات

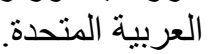

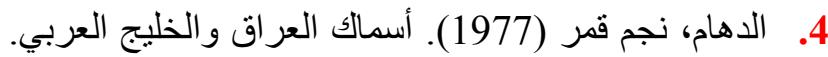
الجزء الاول. منشورات مركز دراسات الخهاتيج العربي.

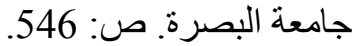
5. الخفاجي، احمد عبد الرحمن (2005). الأسماك غذاء الركاء

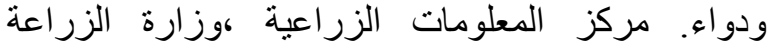

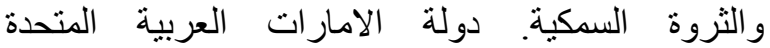
.WWW.Wae.gov.ae

6. Whitaker, J. R. $1977 . \quad$ Enzymatic modification of proteins applicable to foods. In Food Proteins, ed. R. E. Feeney and J. R. 
تركيبه الكيميائي وخو اصده الوظيفية مجلة ديإلى للعلوم

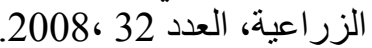

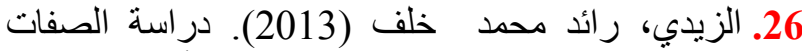

النوعية للزيوت المستخلصة من مخلفات أسماك الجري الهري

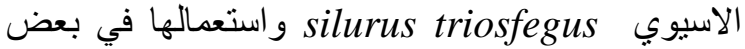
النظم الغذائية رسالة ماجستير، كلية الزرانةاعة-جامعة

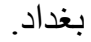

27. البياتي، محمود محمد احمد وعبد الرحيم، بتول عبد الريد

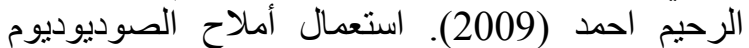

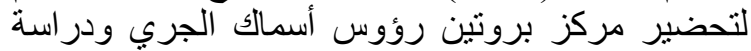
تركيبه الكيميائي وخواصنه برونين الفيزيائية. مجلة ديألّى للعلوم

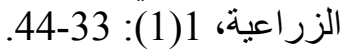
28. جاسم، منير عبود (12011).

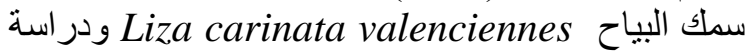
صفاته النوعية. مجلة ابحاث البصرة البعات (العلميات)، العدد السابع و الثلاثون، الجزء ع الر ابع.

29. Xu, L. and Diosady, L. L. (1994). Funtional properties of Chinese rapeseed protein isolates. J. food Sci., 59(5):1127-1130.

30. محمد، أمير عباس (2009). تصنيع مركزات بروتينية

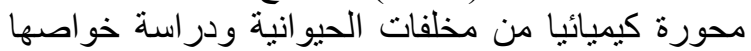
الوظيفية. رسالة ماجستير. كلية الزراعة - جامعة الية

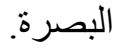

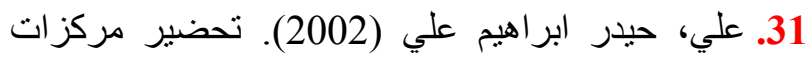

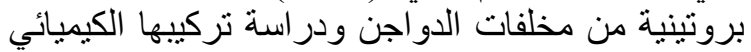

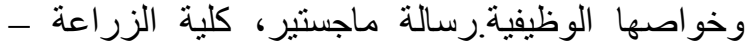

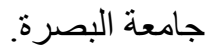

32. Waniska, R. D.; Shetty, J. K. and Kinsella, J. E. (1981). Protein stabilized emulsions: effects of modification on the emulsifing activity of boving serum albumin in a model system. Agric. Food Chem., 29: 826 -831.

33. Huang, Y.T and Kinsella, J. E. (1987). Effects of phosphorylation on emulsifying and foaming properties and digestibility of yeast protein. J. Food Sci., 52: 1684-1688.

34. البياتي، محمود محمد أحمد (1997). فصل بروتينات

سمك الحف (forskal dorab chirocentrus) الرئيسة

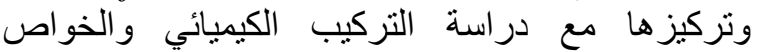
الوظيفية للمنتج النهائي ـ رسالة ماجستير ـ كلية الزر اعة النئ

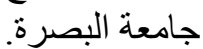

35. Kinsella, J. E. (1976). Functional properties of protein in foods: A survey crit. Rev. food Sci. Nutr., 4: 219 -228.

36. عبد الرحيم، بنول عبد الرحيم احمد (1999). دراسة

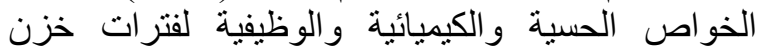

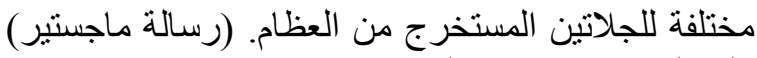
كلية الزر اعة ـ جامعة البصرة. صن: 75.
12. Pearson, D. (1970). The chemical analysis of food $6^{\text {thed }}$ chemical publishing compamy, inc., New York. P: 604

13. A.O.A.C. (1990). Official methods of analysis. Association of Official Analytical Chemists, Washington, D.C. 13th edition. Pp: 222-225.

14. عواد، كاظم مشحوت (1984). الأختبارات العملية للأسدة، التحليل الكيمياوي للعينات النباتية، كلية الزر اعة، التئة

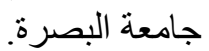

15. Betschart, A. A. (1974). Nitroigen Solubility of alfalfa protein concentrate as influenced by various factors .J. Food Sci., 39: 11101115.

16. Beuchat, L. R. (1977). Functional and electrophoretic characteristics of succinylated peanut flour proteins. J. Agric. Food chem.., 25: 258-261.

17. Jasim, M. A. (1983). Functional plastein from fish wast. Ph.D. thesis "lough borough university of technology" England.

18. Jasim, M. A.; Sahi, A. A. and Faris, J. A. (1988). Studies on the functoional properties and composition of the dried catfish ('s.glanis) products. marin mesopotam: ea. 3(1): 31-42.

19. Sathe, S. K. and Salunkhe, D. K. (1981). Functional properties of the great.northern bean (phaseolus vulgarisl) proteins: emulsion, foaming, viscosity and gelation properties. J. food Sci., 46: 71-74.

20. Miller, R. and Groning, H. S. (1976). Functional properties of enzyme-modified acylated fish protein derivatives. J. food Sci., 41: 268-271.

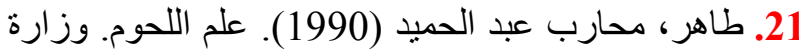

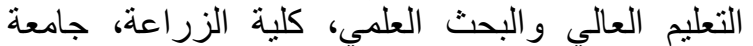

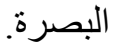

22. البياتي، محمود محمد احمد (2005). إنتاج الجيلاتين من

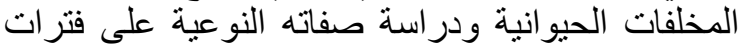
خزنية مختلفة ـ أطروحة دكتور اه، كلية الزر اعة النة - جامعة

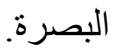

23. Thahir, M. A. (1979). Effect of collagen on measures of meat tenderness. Ph.D. Thesis Univ. Nebraska. Lincoln. Neb.

24. الثطي، صباح ماللك حبيب (2006). دراسة تقنية

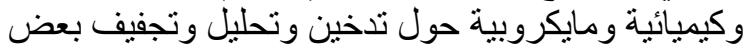

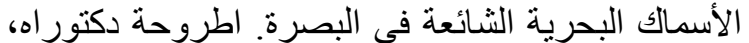
كلية الزر اعة - جامعة البصرة البحة صي البحة 248.

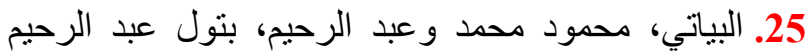
احمد (2008). تحضير البومين سمك البياح ودراسة الرة 


\section{Production of protein modified from cat fish silurus triostegus and study of} quality properties in food systems

\section{Batool Abdulrahem Ahmed and Faraah Tariq Hamad}

Food Science Department, College of Agriculture, Baghdad University, Iraq.

\section{E-mail: abdulrahemb@yahoo.com}

\section{Summary}

The Present study was concerned with utilizing muscles fibers for catfish silurus triostegus to prepare fish protein concentrate modified, the chemical composition, sensory and functional properties were evaluation during storage at (25-30) $\mathrm{C}^{\circ}$ for 35 days and use in food system, the yield percentage $18.6 \%$. The chemical composition of product was contained highest percentage of protein and low moisture, ash and fat during along storage, in addition to that it contained high percentage of minerals (sodium, phosphorus, calcium and potassium) and low zinc. Also this fish protein concentrate have a good functional properties, especially solubility, emulsification, water absorption, fat binding and viscosity it's very good compared to commercial protein. The result also showed had good sensory properties (color and odor) so it light yellow color and the odor was light fish odor and kept this characteristics during storage, when employed in food system, as manufacture of fish balls, the product having a good organoleptic characteristics especially tenderness, juiciness and general acceptance.

Keywords: Concentrate, Protein, System, Food, Silurus triostegus. 